\title{
Correlation of alveolar-arterial gradient with computed tomography pulmonary artery obstruction index in acute pulmonary embolism
}

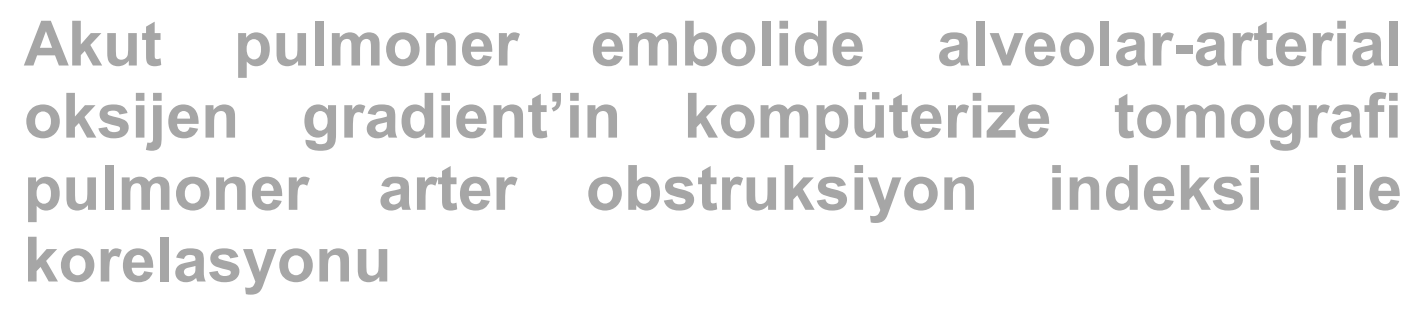

Onur Karakayalı ${ }^{1}$, Serkan Yılmaz ${ }^{1}$, İlyas Ertok ${ }^{3}$, Gülhan Kurtoğlu Çelik ${ }^{2}$, Güll Pamukcu ${ }^{2}$, Yavuz Yiğit ${ }^{1}$, Murat Memiș ${ }^{4}$, Halill Yıldırım ${ }^{5}$

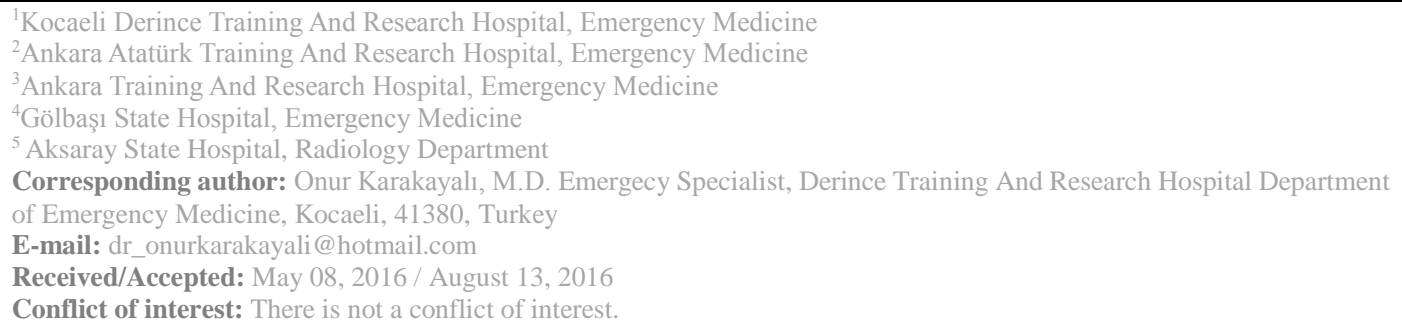

\section{SUMMARY}

Objective: The purpose of our study was to investigate the relationship between the pulmonary artery obstruction index (PAOI) assessed with helical computed tomography (CT) and impairment in blood gases in patients with acute pulmonary embolism (PE).

Method: This retrospective study design was carried out in the Tertiary Training and Research Hospital Emergency Clinic over a 6-month period with patients in whom PE was detected. The Alveolar-arterial (A-a) oxygen gradient for oxygen was calculated according to the formula 150 $1.25(\mathrm{PaCO} 2-\mathrm{PaO} 2)$, and the PAOI for each patient was measured with the Qanadli score at the mediastinal window using chest CT angiography (CTA).

Results: There were 113 patients included in the study; their mean age was $61.40( \pm 16.082)$ years and $51.4 \%$ of the patients were female. The mean Alveolar-arterial (A-a) oxygen gradient value was $65.13( \pm 18.78)$ in massive embolism group. The mean PAOI was determined as 34.027 (min:7.5, max:83.7). The relationship between the radiologically measured PAOI and the Alveolararterial (A-a) oxygen gradient were compared, and an increase in the index was detected as the Alveolar-arterial (A-a) oxygen gradient level increased; this difference was found to be statistically significant $(\mathrm{r}=0.400 ; \mathrm{p}<0.001)$.

Conclusions: This retrospective observational study found a weak but positive correlation between the PAOI and the Alveolar-arterial (A-a) oxygen gradient. Our study showed that consideration of the Alveolar-arterial (A-a) oxygen gradient increases the sensitivity of blood gas analysis in documented pulmonary embolism. All data showed that the Alveolar-arterial (A-a) oxygen gradient values may be clinically beneficial, as such testing is easy to perform and cost-effective.Moreover, it can be performed at the bedside to detect which patients should be treated with thrombolytics.

Keywords: Pulmonary Embolism, Arterial-Alveolar Gradient, Pulmonary Artery Obstruction Index 


\section{ÖZET}

Amaç: Çalışmamızın amacı akut pulmoner emboli saptanan hastalarda helikal bilgisayarlı tomografi ile hesaplanan pulmoner arter obstruksiyon indeksinin (PAOI) kan gazı parametrelerinden alveolar-arterial oksijen gradienti ile ilișkisinin araştırılmasıdır.

Yöntem: Bu retrospektif çalıșmaya 3. Basamak eğitim araștırma hastanesi acil tıp kliniğine 6 aylık dönemde başvuran ve pulmoner emboli tespit edilen hastalar dahil edildi. Alveolar-arterial oksijen gradient "150-1,25(PaCO2-Pa02)" formülu ile hesapland1.

Bulgular: Çalışmaya 113 hasta dahil edildi. Hastaların yaş ortalaması $61.40( \pm 16,082)$ ve \%51.4' ü bayand1. Alveolar-arterial oksijen gradient ortalamas1 masif emboli grubunda $65,13( \pm 18,78)$ saptand1. PAOI ortalamas1 34,027 (min:7,5 max:83,7) idi. PAOI ile alveolar-arterial oksijen gradienti arasındaki ilişki karşılaştırıldığında alveolar-arterial oksijen gradienti yükseldikçe pulmoner arter obstruksiyon indeksinin arttığı ve bu ilişkinin istatistiksel olarak anlamlı olduğu görüldü $(r=0,400 \mathrm{p}<0,001)$.

Sonuç: Bu retrospektif gözlemsel çalışmada PAOI ile alveolar-arterial gradient arasında zayıf ancak pozitif bir korelasyon saptandı. Çalışmamız pulmoner emboli saptanan hastalarda kan gazı analizinde $\mathrm{P}(\mathrm{A}-\mathrm{a}) \mathrm{O} 2$ gradientinin sensitivitesinin arttığını gösterdi. Bütün datalar alveolar-arterial oksijen gradientin kolay uygulanabilinir, düşük maliyetli ve faydalı olabileceğini göstermektedir. Dahası yatak başı uygulamada trombolitik tedavi planlanan hastalarda tanısal alternatif bir seçenek olarak kullanılabilir.

Anahtar sözcükler: Pulmoner Emboli, Alveolar-arterial gradient, Pulmoner Arter Obstruksiyon indeksi

\section{INTRODUCTION}

Pulmonary embolism (PE) is a common and potentially fatal disease with a high mortality rate of $2-7 \%$, even when treated with anticoagulation ${ }^{1,2}$. It is difficult to determine the real number of patients who have PE in the emergency medicine department because there is no reliable way of identifying the missed cases.

In new guidelines for the diagnosis and treatment of acute PE, the European Society of Cardiology recently included computed tomography angiography (CTA) as the reference standard modality to be used following the initial clinical evaluation ${ }^{3}$. Multidetector-row CT pulmonary angiography (CTPA) has become the first-line imaging technique in suspected acute $P E^{4,5}$. In addition CTPA has shown a fast and accurate PE diagnosis with a high negative predictive value $^{6}$, many reports have shown the usefulness of helical CTA in the diagnosis of acute $\mathrm{PE}^{7,8}$. The specific index (the CT obstruction index) that we propose to quantify the degree of arterial vascular obstruction in helical CT appears simple, reproducible and highly correlated to a previously described index with selective pulmonary angiography. The CT obstruction index could be used to grade the severity of PE and to monitor patients requiring an objective repetitive evaluation ${ }^{9}$.

The clinical diagnosis of PE can be difficult. Prior to the development and validation of more specific tests for PE, assessment of oxygenation and calculation of the Alveolar-arterial (A-a) oxygen gradient was often used to indicate the perceived risk for PE. The Alveolar-arterial (A-a) oxygen gradient was suggested many years ago as a simple test for PE, but it is still not used in daily practice. In the current population of patients found to have PE, the arterial blood gases and pulse oximetry do not reliably predict the presence or absence of $\mathrm{PE}^{10}$.

Gas exchange abnormalities observed in patients with acute PE are related to the size of the emboli, the presence of underlying cardiopulmonary disease, the degree of obstruction and the time since embolisation ${ }^{11}$. Several studies have proposed that Alveolar-arterial (A-a) oxygen gradient has a linear correlation to the perfusion defect and is a sensitive indicator of resolved emboli (12), but the relationship between the embolic burden of the clot and the Alveolar-arterial (A-a) 
oxygen gradient has been studied in a limited number of studies.

The purpose of our study was to investigate the relationship between the pulmonary artery obstruction index (PAOI) assessed with helical CT and impairment in blood gases in patients with acute PE. We designed this study to investigate whether the quantification of acute PE using the PAOI, as proposed by Qanadli et al. ${ }^{9}$, correlates with the functional lung impairment of acute PE, and more specifically, with the Alveolararterial (A-a) oxygen gradient

\section{MATERIAL AND METHODS}

\section{Settings}

This retrospective single-centre observational study was conducted in the Tertiary Training and Research Hospital's Emergency Clinic, which has a mean annual admission of 108,000 patients. Patients who had been diagnosed with PE according to their chest CTA within a 6-month period were included in the study. The study was approved by the local ethics committee.

\section{Assessment \\ Patients whose files had missing information and patients who had cardiopulmonary arrest and on whom resuscitation was performed were excluded from the study.}

At the time of the presentation, the patients' Wells score was calculated according to their clinical symptoms. Patients with a Wells score of over 6 were prediagnosed as high probability and those with Wells score of over 2 were prediagnosed as moderate probability PE. Patients with high quantitative Ddimer blood levels were prediagnosed as PE and a chest CTA was performed. Complete blood count, biochemical profile, troponin I and D-dimer tests were performed; radial arterial blood gases with arterial puncture were obtained in the first hour of presentation at room temperature. Arterial blood gases, including arterial partial pressure of oxygen $\left(\mathrm{PaO}_{2}\right)$, arterial partial pressure of carbon dioxide $\left(\mathrm{PaCO}_{2}\right)$ and arterial oxygen saturation $(\mathrm{SaO} 2)$, were measured on admission to the emergency department with the patient breathing room air. Furthermore, Alveolar-arterial (A-a) oxygen gradient was calculated according to the following formula:

$\mathrm{PAO}_{2}-\mathrm{PaO}_{2}$ gradient $(\mathrm{mm} \mathrm{Hg})=150-$ $1.25(\mathrm{PaCO} 2-\mathrm{PaO} 2) .{ }^{13}$

\section{CT imaging protocol}

Based on our own experience with CTPA, the standard delay was increased from 4 to $7 \mathrm{~s}$ in order to provide sufficient contrast in the pulmonary arterial vasculature to simultaneously assess embolic vessel occlusion and sufficient iodine distribution in the lung parenchyma. One hundred millilitres of high-concentration contrast material (Iopromide, Ultravist 300, Bayer Schering Pharma, Berlin, Germany) were administered via an antecubital vein at a flow rate of $4 \mathrm{~mL} / \mathrm{s}$, followed by $50 \mathrm{~mL}$ of saline injected at the same flow rate. The imaging was begun using a bolustracking technique with a threshold of $100 \mathrm{HU}$ in the pulmonary trunk, adding the above-mentioned delay of 7 seconds for the contrast medium arrival time. To reduce streak artefacts caused by dense contrast material in the superior vena cava, the imaging was performed in a caudocranial direction.

All CTPA examinations were independently read by a radiologist.Clot burden scores were calculated retrospectively for all patients with positive CTPA examinations for PE.

The diagnosis of PE was made according to the presence of intraluminal filling defect in the main pulmonary artery, or the right and left pulmonary artery, at the lobar, segmental and if detection was possible, subsegmental levels on the CTPA scans. The PAOI was measured with the Qanadli score at the mediastinal window in the chest CTA for each patient.

\section{The Qanadli score}

The pulmonary arteries are subdivided into 10 segmental arteries in each lung (three in the upper lobe, two in the middle lobe and lingula and five in the lower lobe). The presence of an embolus in a segmental artery is scored as 1 point, and 
more proximal emboli are scored at a value equal to the number of segmental branches arising from the affected vessel. Each score is multiplied by 0,1 or 2 according to the estimated degree of vascular occlusion $(0=$ no obstruction; 1=partial occlusion; $\quad 2=$ complete occlusion). A subsegmental embolus is considered an embolus in the corresponding segmental artery with partial occlusion (scoring $1 \times 1=1$ ). The Qanadli score ranges from 0 (normal) to 40. The percentage value is then calculated as $\Sigma(n \times d) / 40 \times 100[n=$ score of the embolus multiplied by the number of dependent segments $(\min =1 ; \max =20)$; $\mathrm{d}=$ degree $\quad$ of obstruction $\quad(\mathrm{min}=0$, $\max =2)]$.

The patients were evaluated according to their clinical and CTA findings and grouped into the clinical categories of acute PE as follows: massive, submassive and non-massive embolism. The pulmonary artery pressure, ejection fraction and right ventricular diameter measurements in all the patients diagnosed with PE were recorded using transthoracic echocardiography (TTE). The lower extremity venous Doppler ultrasonography findings of all the patients were recorded from the hospital archives.

\section{Statistics}

The mean Alveolar-arterial (A-a) oxygen gradient level of all patients was found to be $49.090 \quad( \pm 15,82)$. When the patients'demographic data were compared with their Alveolar-arterial (A-a) oxygen gradient levels, no statistically significant difference was found between the Alveolar-arterial (Aa) oxygen gradient and age or gender ( $\mathrm{p}=0.284 ; \mathrm{p}=0.724)$.

Using the chest CTA findings of the patients with PE, the PAOI was measured by the radiology clinic. The mean PAOI was determined to be 34.027 (min:7.5, $\max : 83.7)$.

When the relationship between the radiologically measured PAOI and the Alveolar-arterial (A-a) oxygen gradient were compared, an increase in the index
The IBM SPSS Statistics Version 21.0 pocket programme was used for the statistical analyses. The quantitative variables were summarised with mean \pm standard deviation and median (minimum - maximum) values. The categorical variables were presented in numbers and percentages. The intergroup differences of quantitative variables were evaluated with the $t$ test in independent groups when the statistical test hypotheses were fulfilled and with the Mann Whitney U test when the hypotheses were not fulfilled. The relationships between the quantitative variables were analysed using the Pearson correlation coefficient. A p-value of less than 0.05 was accepted as statistically significant.

\section{RESULTS}

One hundred and twenty-five patients who presented to the emergency department in a 6-month period and were diagnosed with PE according to CTA reports were included in the study. Of these 125 patients, 12 patients' files had missing data and those patients were excluded. The remaining 113 patients' were included in statistical analysis.

The demographic data, clinical characteristics and laboratory results of the patients are summarised in Tables 1 and 2 .

was detected as the Alveolar-arterial (Aa) oxygen gradient level increased. The difference was found to be statistically significant $(r=0.400 ; p<0.001$; figure 1$)$.

Echocardiography showed enlargement of the right chamber in 74 patients $(65.4 \%)$. The pulmonary arterial pressure was over 35 in 31 patients $(27,4 \%)$, while the mean pulmonary arterial pressure was determined to be 49.15 (min:25, max:100). No positive correlation was detected when the arterial-alveolar gradient and the echocardiographic pulmonary arterial pressure of the patients were compared $(\mathrm{r}=0.164$; $\mathrm{p}=0.082$ ). Deep venous thrombosis (DVT) was determined on lower extremity venous Doppler ultrasonography in 56 patients $(49.55 \%)$. 
The Alveolar-arterial (A-a) oxygen gradient values of the patients with acute DVT compared to the patients without
DVT were not statistically significantly different $(\mathrm{p}=0.487)$.

Table 1. Demographic and clinical characteristics of the patients

\begin{tabular}{|c|c|}
\hline \multicolumn{2}{|l|}{ Age,years } \\
\hline All $(\mathrm{m} \pm \mathrm{SD})$ & $61.40( \pm 16.082)$ \\
\hline \multicolumn{2}{|l|}{$\operatorname{Sex}, n(\%)(M)$} \\
\hline Male & $55(48.6 \%)$ \\
\hline \multicolumn{2}{|l|}{ Clinical presentation, n(\%) } \\
\hline Dyspnoea & $75(66.3 \%)$ \\
\hline Chest pain & $52(46.1 \%)$ \\
\hline Haemoptysis & $22(19.4 \%)$ \\
\hline Fever & $13(11.5 \%)$ \\
\hline Syncope & $8(7.07 \%)$ \\
\hline \multicolumn{2}{|l|}{ Vital signs } \\
\hline Pulse,beat/min & 113.39 \\
\hline Systolic arterial pressure $(\mathrm{mmHg})$ & 118.29 \\
\hline Diastolic arterial pressure $(\mathrm{mmHg})$ & 72.89 \\
\hline
\end{tabular}

M: Male, SD: Standard deviation, n: number

min: minute $\quad \mathrm{mmHg}$ : millimetres of mercury

Table 2. Laboratory findings

\begin{tabular}{|l|c|c|c|}
\hline & Massive embolism & Sub-massive embolism & Non-massive embolism \\
\hline Patients (n) & 6 & 50 & 57 \\
\hline $\begin{array}{l}\text { D-Dimer (ng/ml) (M, } \\
\text { IQR) }\end{array}$ & $5621(4587-8000)$ & $4558(3192.5-7368)$ & $2513.5(1529.5-5459.5)$ \\
\hline $\begin{array}{l}\text { Troponin (ng/ml) (M, } \\
\text { IQR) }\end{array}$ & $0.259(0.052-1.17)$ & $0.058(0.01-0.48)$ & $0.014(0.009-0.067)$ \\
\hline $\begin{array}{l}\text { Gradient }(\mathrm{mmHg}) \\
(\mathrm{m} \pm \text { SD) }\end{array}$ & $65.13 \pm 18.78$ & $53.26 \pm 15.19$ & $45.19 \pm 14.43$ \\
\hline
\end{tabular}

n: number, m: mean, M: median, IQR: interquartile range, ng/ml: nanogramme/decilitre, SD: standard deviation 


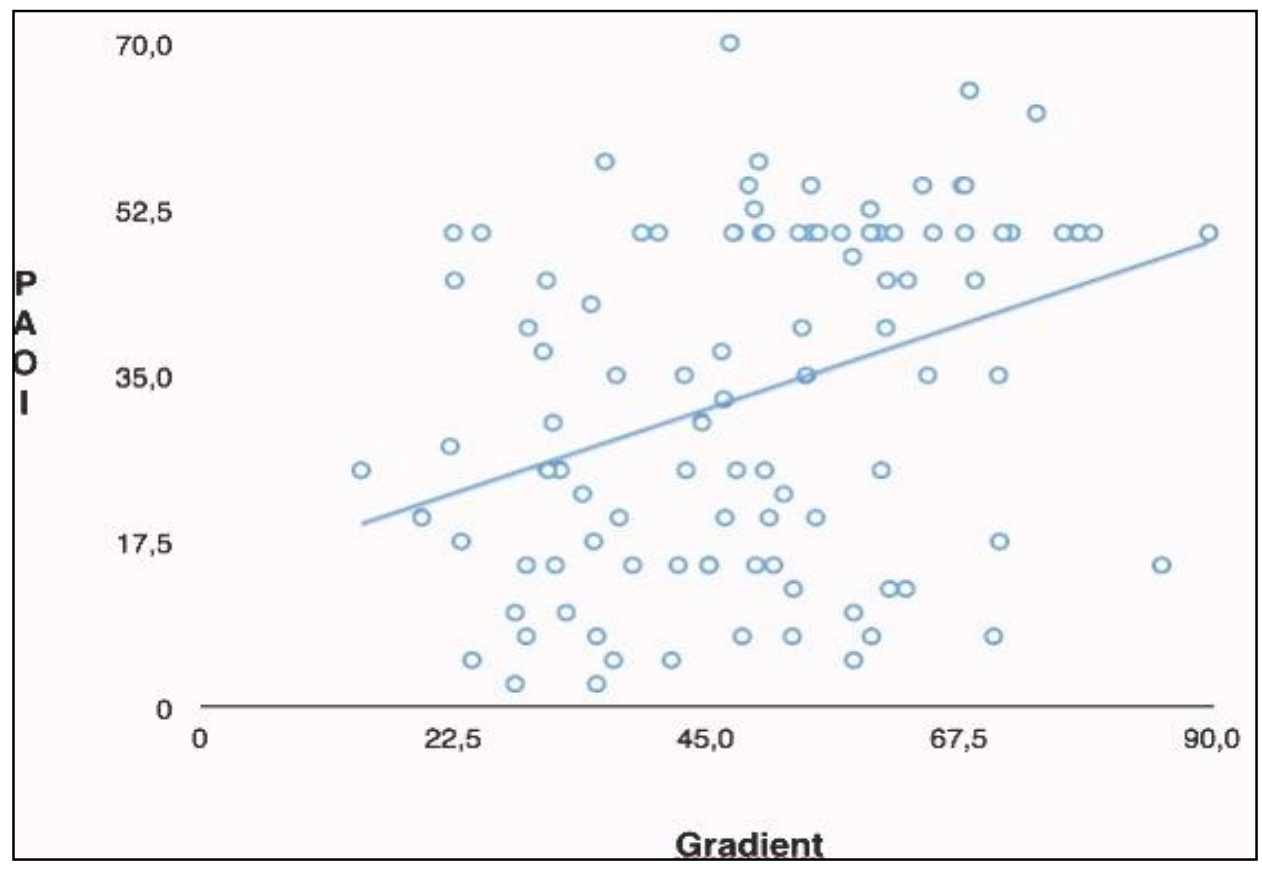

Figure 1. Correlation between the alveolar-arterial gradient and pulmonary artery obstruction index in pulmonary embolism

The evaluation of 113 patients with their clinical data and pulmonary arterial CT index showed non-massive embolism in $57(50.5 \%)$, sub-massive embolism in 50 $(44.2 \%)$ and massive embolism in 6 (5.3\%) patients.

Thrombolytic treatment was given to 30 patients in the light of clinical, echocardiographic and chest CTA findings. They represented $26.54 \%$ of all patients.

When the alveolar-arterial gradient values were compared, the patients who had thrombolytic treatment had higher values than the patients who had not been treated.However, the difference was found to be statistically non-significant $(\mathrm{p}=0.006$; Figure 2).

When the Alveolar-arterial (A-a) oxygen gradient was compared with d-dimer and troponin in the laboratory data of the patients, no significant difference was found between the Alveolar-arterial (Aa) oxygen gradient level and the d-dimer level $(\mathrm{p}=0.642)$ or troponin level $(p=0.368) . \quad$ A statistically significant positive correlation was found between the d-dimer level and the troponin level $(\mathrm{p}=0.004)$.

When the relationships between the levels of the Alveolar-arterial (A-a) oxygen gradient, $\mathrm{d}$-dimer and troponin of the patients with massive embolism were evaluated, the Alveolar-arterial (A-a) oxygen gradient level was found to be higher than that in patients without massive embolism, and the difference was statistically significant $(\mathrm{p}=0.003)$. No statistically significant positive correlation was determined between the massive embolism and d-dimer level $(\mathrm{p}=0.093)$ or troponin level $(\mathrm{p}=0.116)$. No statistically significant difference was observed between the patients with massive embolism and the patients without massive embolism $(p=0.185)$. 


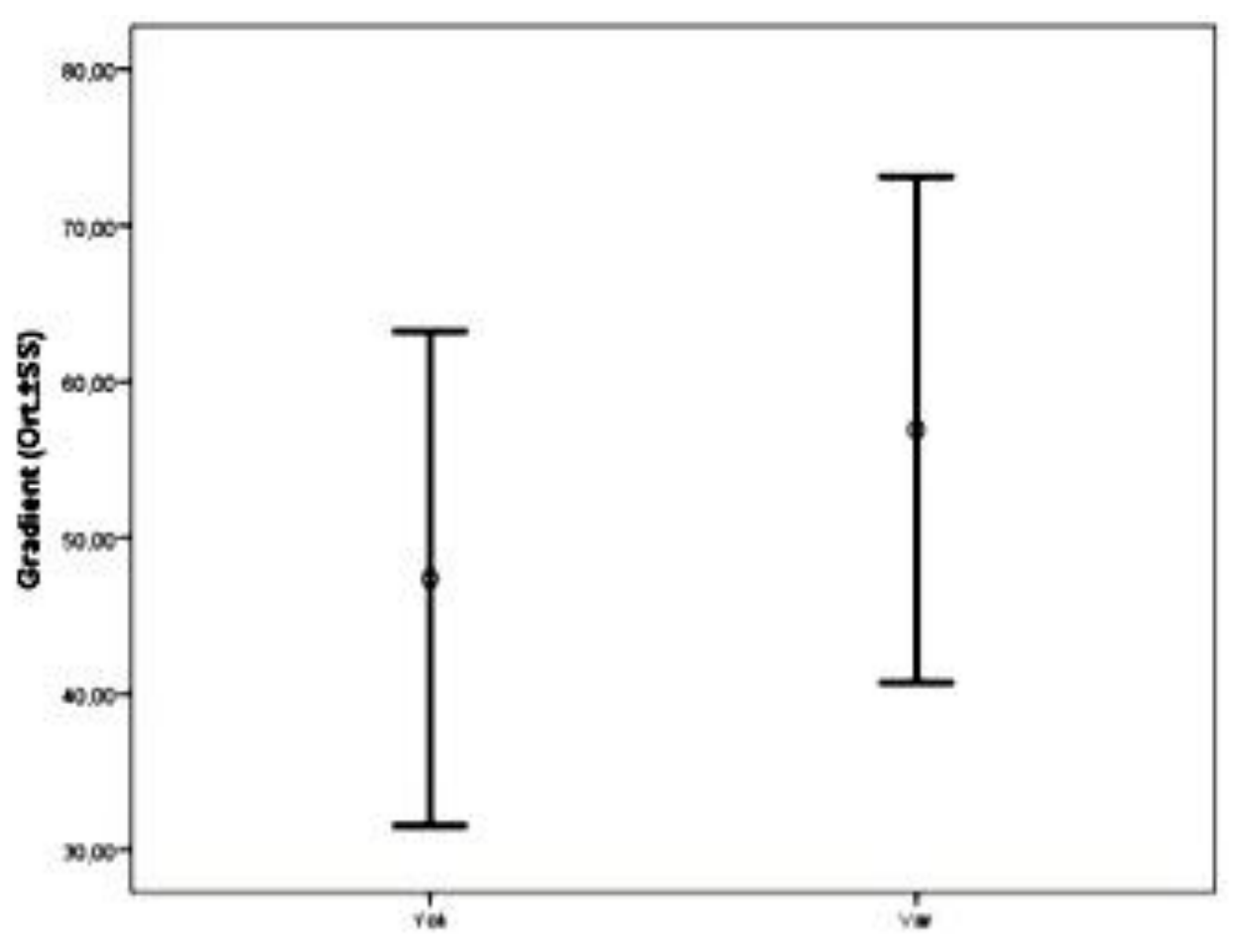

\section{Thrombolytic therapy}

Figure 2. The Value of the alveolar-arterial gradient in the group administered thrombolytics

\section{DISCUSSION}

This retrospective observational study found a weak but positive correlation between the PAOI index and the Alveolar-arterial (A-a) oxygen gradient. Our study shows that consideration of the Alveolar-arterial (A-a) oxygen gradient increases the sensitivity of blood gas analysis in documented PE. Recent studies have shown that the degree of arterial obstruction in PE may be quantified by a specific CT index that appears reproducible and highly correlated to the previously described index with pulmonary angiography.

The introduction of CTPA has made it possible to image the pulmonary arterial tree faster with submillimetrecollimation, thereby improving the overall quality and increasing the sensitivity for isolated subsegmental PE (14-15). However, the interpretation of CTPA is mainly focussed on the presence or published absence of embolism and a rough estimation of its severity (massive, extensive or isolated). A few articles have confronted the challenge of quantifying pulmonary arterial tree obstructionby developing an obstruction index. ${ }^{16,17}$ In our study, the obstruction index of Qanadli et al. ${ }^{9}$ was used due to the simplicity of applying it in routine clinical practice.

Cvitanic conducted the first systematic but small-scale analysis of the Alveolararterial (A-a) oxygen gradient in patients with acute PE who were breathing room air. In this study, increased Alveolararterial (A-a) oxygen gradient was the single most sensitive blood gas parameter in the patients studied, being present in 74 of the 78 patients $(95 \%)^{18}$. One commonly held misconception, contrary to the evaluation of 768 patients participating in the multi-center PIOPED study, which found that between $25 \%$ and $35 \%$ of patients with confirmed PE had 
normal arterial blood gases, pulse oximetry and Alveolar-arterial (A-a) oxygen gradient $^{10}$. A retrospective evaluation of 152 consecutive patients by Jones et al. supported the finding that the absence of an Alveolar-arterial (A-a) oxygen gradient with arterial blood gas results was insufficient to properly rule out PE. However, this study only evaluated the sensitivity of blood gas analysis in documented PE. Specificity, or the ability of an abnormal test to exclude other diseases, was not addressed.

Zafira and colleagues showed that the CT obstruction index used in this study demonstrated a strong correlation between the severity of arterial bed obstruction and the blood gas values in patients with acute PE and no underlying cardiopulmonary disease. The strongest correlation was observed between the index and Alveolar-arterial (A-a) oxygen gradient. Moreover, an obstruction index of greater than $50 \%$ of the arterial bed may be expected for $\mathrm{PaCO} 2$ of $30 \mathrm{mmHg}$ or lower ${ }^{19}$. The results of that study revealed that the PAOI correlated significantly with all blood gas values. However, the strongest correlation was observed between the PAOI and Alveolar-arterial (A-a) oxygen gradient. In our study, we also found a statistically significantly higher Alveolar-arterial (Aa) oxygen gradient value in patients with massive embolism compared to patients without massive embolism, diagnosed according to the radiological thrombus load. In the literature, two small-scale studies have evaluated the relationship between the PAOI and short-term mortality. In one of these studies, Wu et al. ${ }^{20}$ reported that patients with a pulmonary angiographic clot score of higher than $60 \%$ tended to die. These authors and van der Meer et al. ${ }^{21}$ found the clot burden score proposed by Qanadli et al. ${ }^{16}$ to be a significant predictor of death, with positive results on CTPA $(p<0.002)$. However, no study has evaluated the relationship between the Alveolar-arterial (A-a) oxygen gradient and massive embolism. For patients who have been radiologically diagnosed with massive embolism and for whom thrombolytic treatment has been planned, a search for a noninvasive, reachable, bedside methods constitutes the basis of many studies.In our study there was massive embolism in six $(5.3 \%)$ patients.

When the arterial-alveolar gradient values of patients who had thrombolytic treatment in accordance with clinical, echocardiographic and chest CTA findings were compared with the patients who had not undergone the treatment, their Alveolar-arterial (A-a) oxygen gradient values were found to be higher. However, the difference was found to be statistically non-significant. All these data show that testing the gradient values may be beneficial, as such testing is easy to perform and cost-effective. Moreover, it can be carried out at the bedside to determine which patients should be treated with thrombolytics.However, we think that further studies are needed to verify the accuracy of these data.

The limitations for this study were as follows: it was a retrospective, singlecentre study, which limited the number of cases; factors that can affect the Alveolar-arterial (A-a) oxygen gradient such as age and gender could not be standardised and there was no control group; and patients who had been resuscitated and probably had a massive embolism were excluded from the study. The Formula of the A-a $\left(\mathrm{O}_{2}\right)$ was simplified from the original formula in this paper $(150-1.25(\mathrm{PaCO} 2-\mathrm{PaO} 2))$. On the other hand Patm may be change Alveolar-arterial (A-a) oxygen gradient according to altitude. $\left(\mathrm{A}-\mathrm{a}\left(\mathrm{O}_{2}\right)=\right.$ $\left(\mathrm{Fi}_{\mathrm{O}} \% / 100\right) *\left(\mathrm{P}_{\mathrm{atm}}-47 \mathrm{mmHg}\right)-$ $\left.\left(\mathrm{Pa}_{\mathrm{CO}} / 0.8\right)-\mathrm{PaO}_{2}\right)$

We have no information on baseline clinical data like associated comorbidities that can have elevated Alveolar-arterial (A-a) oxygen gradient. Because of the retrospective design, 12 patients had to be excluded due to incomplete files. The number of patients in the massive embolism group was small. In addition, because only patients with PE were included in the study, the 
negative predictive value of the gradient could not be measured.

Our study found a significant relationship between the PAOI, which determines the embolism load in PE, and the Alveolararterial (A-a) oxygen gradient. It was determined that the Alveolar-arterial (Aa) oxygen gradient increases proportionally with the degree of obstruction. The higher Alveolar-arterial (A-a) oxygen gradient values compared to other embolism cases in the massive embolism cases that were detected radiologically predict that the Alveolararterial (A-a) oxygen gradient may be used as a diagnostic tool in detecting the mortality rate in PE; however, further studies are needed to support our research.

\section{REFERENCES}

1. Carson JL, Kelley MA, Duff A, et al. The clinical course of pulmonary embolism. N Engl J Med 1992; 326: 1240-5.

2. Goldhaber SZ, Visani L, De Rosa M. Acute pulmonary embolism: clinical outcomes in the Inter- national Cooperative Pulmonary Embolism Reg- istry (ICOPER). Lancet 1999; 353: 1386-9.

3. Torbicki A, Perrier A, Konstantinides $\mathrm{S}$ et al. Guidelines on the diagnosis and management of acute pulmonary embolism: the Task Force for the Diagnosis and Management of Acute Pulmonary Embolism of the European Society of Cardiology (ESC). Eur Heart J 2008; 29: 2276-315.

4. Wildberger JE, Mahnken AH, Das M, Kuttner A, Lell M, Gunther RW. CT imaging in acute pulmonary embolism: diagnostic strategies. Eur Radiol 2005; 15: 919-29.

5. Schoepf UJ, Costello P. CT angiography for diagnosis of pulmonary embolism: state of the art. Radiology 2004; 230: 329-37.

6. Krestan CR, Klein N, Fleischmann $\mathrm{D}$ et al. Value of negative spiral CT angiography in patients with suspected acute PE: analysis of PE occurrence and outcome. Eur Radiol 2004; 14: 93-8.

7. Goodman LR, Curtin JJ, Mewissen MW, et al. De- tection of pulmonary embolism in patients with unresolved clinical and scintigraphic diagnosis: helical CT versus angiography. AJR 1995; 164: 136974.

8. Senac J, Vernhet H, Bousquet C, et al. Emboli 9. Qanadli SD, El Hajjam M, Mesurolle B, et al. Pro- spective evaluation of dual-slice helical CT in pul- monary embolism: comparison with selective pulmonary angiography in 157 patients. Radiology 2000; 217: 44755.

9. Salah D. Qanadli, Mostafa El Hajjam, Antoine Vieillard-Baron, Thierry Joseph, Benoit Mesurolle New CT Index to Quantify Arterial Obstruction in Pulmonary Embolism: Comparison with Angiographic Index and Echocardiography AJR 2001; 176: 1415-20.

10. Stein PD, Goldhaber SZ, Henry JW, et al. Arterial blood gas analysis in the assessment of suspected acute pulmonary embolism. Chest 1996; 109: 78-81.

11. D'Alonzo GE, Dantzker DR. Gas exchange alterations following pulmonary thromboembolism. Clin Chest Med 1984; 5: 411-9.

12. Stein PD, Goldhaber SZ, Henry JW, Miller AC. Arterial blood gas analysis in the assessment of suspected acute pulmonary embolism. Chest 1996; 109: 78-81.

13. Gunter CA. Respiratory function of the lungs and blood. In: Gunter CA, Welch MH, eds. Pulmonary Medicine.2nd.ed. Philadelphia: JB Lippincott. 1982; 168.

14. Ghaye B, Szapiro D, Mastora I, et al. Peripheral pulmonary arteries: how far in the lung does multidetector row spiral CT allow analysis? Radiology 2001; 219: 629-36

15. Patel S, Kazerooni E, Cascade P. Pulmonary embolism: optimization of small pulmonary artery 
visualization at multi-detector row CT. Radiology 2003; 227: 455-60.

16. Bankier AA, Janata K, Fleischmann $D$, et al. Severity assessment of acute pulmonary embolism withspiral CT: evaluation of two modified angiographic scores and comparison with clinical data. J Thorac Imaging 1997; 12: 150-8.

17. Collomb D, Paramelle PJ, Calaque $\mathrm{O}$, et al. Se- verity assessment of acute pulmonary embolism: evaluation using helical CT. Eur Radiol 2003; 13: 1508-14.

18. Oliver Cvitanic. M.D.:t and Paul L. Marino, M.D., Ph.D. Improved Use of Arterial Blood Gas Analysis in Suspected Pulmonary Embolism Chest I 95 I 1 I January, 1989 Pg:485.

19. Zafiria M. Metafratzil Miltos P. Vassiliou2 George C. Maglaras2 Froso G. Katzioti1 Acute Pulmonary Embolism: Correlation of CT Pulmonary Artery Obstruction Index with Blood Gas Values AJR 2006; 186: 213-9.

20. McFarlane MJ, Imperiale TF. Use of the alveolar-arterial oxygen gradient in the diagnosis of pulmonary embolism [published erratum appears in Am J Med 1998; 105:458]. Am J Med 1994; 96: $57-$ 62.

21. Rathan M. Subramaniam,Jay M., Catherine C. et al. Pulmonary Embolism Outcome: A Prospective Evaluation of CT Pulmonary Angiographic Clot Burden Score and ECG ScoreAJR 2008; 190: 1599-604. 